NISTIR 89-4050

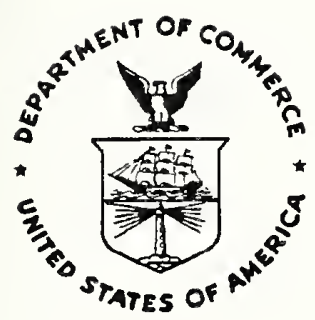

\title{
Fire Induced Flows in Corridors -- A Review of Efforts to Model Key Features
}

K. D. Steckler

U.S. DEPARTMENT OF COMMERCE

National Institute of Standards and Technology

(Formerly National Bureau of Standards)

National Engineering Laboratory

Center for Fire Research

Gaithersburg, MD 20899

February 1989

Sponsored by:

General Services Administration

Washington, DC 20405 



\title{
Fire Induced Flows in Corridors -- A Review of Efforts to Model Key Features
}

\author{
K. D. Steckler
}

U.S. DEPARTMENT OF COMMERCE

National Institute of Standards and Technology

(Formerly National Bureau of Standards)

National Engineering Laboratory

Center for Fire Research

Gaithersburg, MD 20899

February 1989

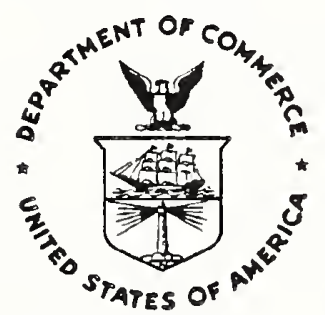

National Bureau of Standards became the National Institute of Standards and Technology on August 23, 1988, when the Omnibus Trade and Competitiveness Act was signed. NIST retains all NBS functions. Its new programs will encourage improved use of technology by U.S. industry.

Sponsored by:

General Services Administration

Washington, DC 20405

U.S. DEPARTMENT OF COMMERCE

Robert A. Mosbacher, Secretary

Ernest Ambler, Acting Under Secretary for Technology

NATIONAL INSTITUTE OF STANDARDS

AND TECHNOLOGY

Raymond G. Kammer, Acting Director 
Table of Contents

$\underline{\text { Page }}$

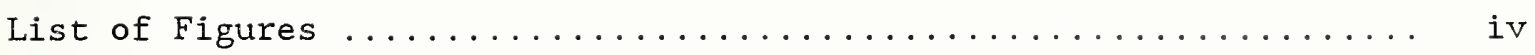

Abstract $\ldots \ldots \ldots \ldots \ldots \ldots \ldots \ldots \ldots \ldots \ldots \ldots \ldots \ldots \ldots \ldots \ldots \ldots$

1. Introduction $\ldots \ldots \ldots \ldots \ldots \ldots \ldots \ldots \ldots \ldots \ldots \ldots \ldots \ldots \ldots \ldots \ldots$

2. Forward Gravity Current .......................... 2

3. Return Gravity Current ...................... 5

4. Uniform Filling $\ldots \ldots \ldots \ldots \ldots \ldots \ldots \ldots \ldots \ldots \ldots \ldots \ldots \ldots \ldots \ldots$

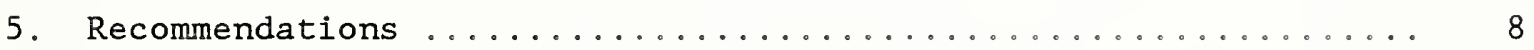

6. $\operatorname{References} \ldots \ldots \ldots \ldots \ldots \ldots \ldots \ldots \ldots \ldots \ldots \ldots \ldots \ldots \ldots$

7. Nomenclature ..................................... 11 
$\underline{\text { Page }}$

Figure 1. Basic Features of Corridor Flow [1] .............. 13

Figure 2. Parameters for Analysis of Gravity Current with Heat Transfer (no mixing) .................... 14

Figure 3. Comparison of Calculated and Experimental

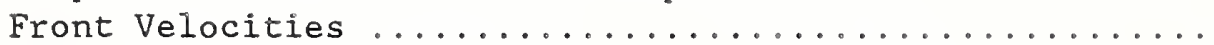

Figure 4. Comparison of Calculated and Experimental Thickness of Forward Gravity Current .................... 16

Figure 5. Flow Path Following Impingement of Gravity Current

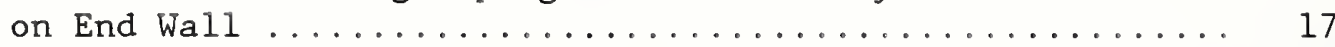

Figure 6. Room Filling [1] ....................... 18

Figure 7. Effect of Aspect Ratio on Filling Pattern ........... 19

Figure 8. Enclosure Flow Dynamics Consistent with ASET Model [2] ... 20 


\title{
FIRE INDUCED FLOWS IN CORRIDORS - - A REVIEW \\ OF EFFORTS TO MODEL KEY FEATURES
}

K.D. Steckler

\begin{abstract}
A literature review was undertaken to identify engineering formulas or models which can be used to predict key features of the corridor-filling process. The results of that review are presented and assessed. The filling process is viewed as a series of three events: a forward gravity current moving away from the fire source, a reflected or return gravity current moving toward the source, followed by uniform filling of the entire corridor. Recommendations for estimating the filling process during each of these stages are presented.
\end{abstract}

\section{INTRODUCTION}

Corridors often serve as conduits for transporting life-threatening combustion products from localized fires to other areas of a building. For example, combustion products from a fire developing in an office often pass through a doorway or other penetration to an adjacent corridor where they establish a buoyancy-driven flow beneath the ceiling. Figure 1 illustrates the basic features of this flow as outlined by Zukoski [1]. Initially a "forward" gravity current of heated gas propagates away from the fire source along the ceiling of the corridor. Since buoyancy drives the flow, any loss of buoyancy due to heat transfer from the hot gas reduces the velocity of the front and also increases its depth. Upon striking the end wall, the flow reverses and forms a "return" current or wave beneath the existing layer. Eventually the waves disappear, and the layer tends to fill (thicken) uniformly.

This scenario suggests that the corridor filling process can be modeled in two phases; a relatively short initial phase in which horizontal flow phenomena are significant, followed by a much longer uniform-filling phase during which horizontal effects are small. The latter is considerably simplier and easier to model. Indeed, the uniform-filling process is precisely the process modeled by well-established control-volume or "zone" fire-growth models [2-4].

The initial phase is less well understood. For some applications, such as fire-resistance assessment, this is a moot point because the initial phase can be neglected. In others, it cannot be neglected because the time scale of the gravity current phenomena is not small relative to the time scale of the process of interest. Gravity-current fronts are known to propagate away from 
large fires at initial speeds typically in the range 0.2 to $2.0 \mathrm{~m} / \mathrm{s}^{1}[1,5]$. For "typical" corridors having moderate to long lengths, the time scale for the front to transit the length of the corridor could be on the order of minutes. During this period, there could be dramatic variations in conditions along the length of the corridor which have a bearing on fire-protection issues such as detection and escape time.

The objective of the current work is to identify or develop engineering formulas or models which predict the key features of the corridor filling process. These predictive methods combine gravity-current models for the relatively short initial stage and zone models for the subsequent and longer uniform-filling stage.

\section{FORWARD GRAVITY CURRENT}

Benjamin's [7] work on general gravity currents serves as a basis, or at least a reference point, for studies of fire-induced forward gravity currents. He found that for an inviscid fluid without mixing the front or "nose" of an energy-conserving gravity current moved into a stagnant fluid with a velocity, $v_{f}$, given by the expression

$$
v_{f}=\left(g \Delta \rho \delta / 2 \rho_{\infty}\right)^{\frac{3}{2}}
$$

where $g$ is gravitational acceleration, $\delta$ the depth of the current, $\rho_{\infty}$ the density of the stagnant fluid, $\Delta \rho=\rho_{\infty}-\rho$, and $\rho$ is the density of the gravity current. Benjamin expanded the theory to account for energy dissipation due to friction at the wall or turbulence. Hinkley [8] applied the latter theory to fire-induced corridor flows. Using the ideal gas law to express the density difference $\Delta \rho$ in terms of the temperature difference $\Delta \mathrm{T}=\mathrm{T}-\mathrm{T}_{\infty}$, he obtained

where

$$
\begin{gathered}
v_{f}=C U^{\prime}((H-\delta)(2 H-\delta) /[H(H+\delta)]\}^{1 / 3} \\
U^{\prime}=\left[g \dot{q}^{\prime} T /\left(c_{p} \rho_{\infty} T_{\infty}^{2}\right)\right]^{1 / 3}
\end{gathered}
$$

and $\mathrm{C}$ is an empirical constant to account for dissipation, $\mathrm{H}$ is the height of the corridor, ' ${ }^{\prime}$ is the heat flow rate in the layer at the front per unit corridor width, $\mathrm{T}$ is the absolute temperature of the layer, $\mathrm{T}_{\infty}$ the temperature of the stagnant layer having density $\rho_{\infty}$, and $c_{p}$ is the specific heat of the stagnant layer. Benjamin found $C$ to be approximately 0.8 . The velocity of the front can also be expressed in terms of the mass flow rate to the layer, m, as

${ }^{1}$ It is important to note that the present review addresses buoyancydriven non-reacting gravity currents during the early stages of a fire. Corridor flow velocities greater than $2 \mathrm{~m} / \mathrm{s}$ can occur in fire situations in which forced and/or reacting flows are present in the corridor. Emmons [6] addresses some of these issues including the possibility of a rapidly moving smoke pulse due to roof collapse. 


$$
\mathrm{v}_{\mathrm{f}}=\dot{\mathrm{m}} /(\rho \mathrm{W} \delta)=\dot{\mathrm{m} T} /\left(\rho_{\infty} \mathrm{T}_{\infty} \mathrm{W} \delta\right)
$$

where $W$ is the width of the corridor. Eqs. (2-4) allow the velocity of the front and the depth of the layer to be calculated when the heat flow to the layer per unit width, the mass flow to the layer, and the temperature of the mass flow are known. It is important to note that Eqs. (2-4) assume constant $\dot{q}^{\prime}$, constant $\dot{m}$, and no heat loss from the layer.

Hinkley also examined the case in which heat is transferred from the hot gravity current to the ceiling and walls of the corridor. As mentioned above, heat transfer will decrease the frontal velocity as the front progresses down the corridor. Assuming no variation with height of the temperature within the gas layer, invoking the Boussinesq approximation $\left(\rho \rightarrow \rho_{\infty}\right.$, except in the buoyancy term), and using the notation displayed in Fig.2, Hinkley found

$$
\begin{aligned}
\mathrm{v}_{\mathrm{f}}(\mathrm{x}) & =\mathrm{v}_{0} \exp \left[-\mathrm{K}\left(\mathrm{x}-\mathrm{x}_{0}\right)\right] \\
\mathrm{x}_{\dot{f}}-\mathrm{x}_{0} & =\mathrm{K} \ln \left[\left(\mathrm{v}_{0} t / K\right)+1\right] \\
\mathrm{K} & \equiv \mathrm{hW} /\left(3 \dot{\left.\mathrm{m} \mathrm{c}_{\mathrm{p}}\right)}\right. \\
\delta(t) & =\dot{\mathrm{m} t} /\left[\rho_{0} \mathrm{~W}\left(\mathrm{x}_{\mathrm{f}}-\mathrm{x}_{0}\right)\right]
\end{aligned}
$$

where $h$ is the heat transfer coefficient between the hot gas and ceiling, $t$ is time, $x$ is the horizontal coordinate, and subscripts 0 and $f$ denote the source-end of the corridor and the front, respectively. The attendant temperature variation with position along the length of the corridor is given by

$$
T(x)=T_{\infty}+\left(T_{0}-T_{\infty}\right) \exp \left[-3 K\left(x-x_{0}\right)\right] ; \quad x \leq x_{f}
$$

where $\mathrm{T}$ is the temperature of the gravity current, $\mathrm{T}_{0}$ is its temperature at $\mathrm{x}_{0}$, and $\mathrm{T}_{\infty}$ is the temperature of the ceiling and remaining air in the corridor. Note that $\mathrm{T}_{0}, \mathrm{~T}_{\infty}, \dot{\mathrm{m}}$ and $\dot{\mathrm{q}}^{\prime}$ are assumed constant. The velocity $\mathrm{v}_{0}$ appearing in Eq. (5) can be obtained from Eqs. (2-4). Equations (5-9) apply to "warm" (Boussinesq) gas layers which transfer heat to the ceiling.

For "hot gas", Hinkley's analysis can be extended to yield

$$
\begin{aligned}
v_{f}(x)= & v_{0}\left(\left(T_{\infty} / T_{0}\right) \exp \left[-3 \mathrm{~K}\left(\mathrm{x}-\mathrm{x}_{0}\right)\right]\right. \\
& \left.+\left(\left(\mathrm{T}_{0}-\mathrm{T}_{\infty}\right) / \mathrm{T}_{0}\right) \exp \left[-6 \mathrm{~K}\left(\mathrm{x}-\mathrm{x}_{0}\right)\right]\right)^{1 / 3} \\
\delta(\mathrm{t})= & \dot{\mathrm{m} t} /\left[\rho_{0}\left(\mathrm{~T}_{0} / \mathrm{T}_{\infty}\right) \mathrm{W} \xi\right]
\end{aligned}
$$

where

$$
\xi=\left(\mathrm{x}_{f}-\mathrm{x}_{0}\right)+(1 / 3 \mathrm{~K}) \ln \left(\left(\mathrm{T}_{\infty} / \mathrm{T}_{0}\right)+\left[1-\left(\mathrm{T}_{\infty} / \mathrm{T}_{0}\right)\right] \exp \left[-3 \mathrm{~K}\left(\mathrm{x}_{\mathrm{f}}-\mathrm{x}_{0}\right]\right\}\right.
$$

Note that, as required, Eq. (10) reduces to Eq. (5) and Eq. (11) reduces to Eq. (8) as $\mathrm{T}_{0} \rightarrow \mathrm{T}_{\infty}$. Unlike Eq. (5), however, Eq. (10) cannot be easily integrated to produce a closed-form solution for $x_{f}(t)$. Thus Hinkley's 
approach can be applied to the hot-gas case, but numerical methods are required.

Heskestad [5] conducted a series of full-scale corridor-flow experiments in which he determined forward and reverse gravity current propagation velocities. The experimental arrangement was basically a room/corridor configuration with the fire located in the room. Both steady and "t-squared" (heating rate of source increases with the square of time) fires were used. These well-instrumented experiments provide a data base for assessing corridor-flow theories.

Heskestad analyzed his forward-current velocity results in terms of a "slab" model which he developed as part of the study. The model is expressed as

$$
\mathrm{v}_{\mathrm{f}}=(\mathrm{g} \Delta \rho \delta / 2 \rho)^{\frac{1}{2}}
$$

which is similar but not equal to Benjamin's (Eq. (1)) in which $\rho_{\infty}$ appears in the denominator. In contrast to Hinkley, Heskestad defined the convective heat flow per unit corridor width at the source-end of the corridor as

$$
\dot{q}^{\prime}=c_{p} \rho v_{f} \delta \Delta T=c_{p} v_{f} \delta \Delta \rho T_{\infty}
$$

Solving Eq. (13) for $\delta \Delta \rho$ and substituting into Eq. (12) yields

$$
\mathrm{v}_{\mathrm{f}}=\left(\mathrm{g} \dot{\mathrm{q}}^{\prime} / 2 \rho_{\infty} \mathrm{c}_{\mathrm{p}} \mathrm{T}_{\infty}\right)^{1 / 3}
$$

which can be expressed in terms of temperature as

$$
v_{f}=\left\{g \dot{q}^{\prime}\left(1+\Delta T / T_{\infty}\right) /\left(2 \rho_{\infty} c_{p} T_{\infty}\right)\right\}^{1 / 3}
$$

In analyzing his corridor flow data, Heskestad interpreted $\Delta \mathrm{T}$ as the maximum temperature rise, $\Delta T_{m}$, in the flow at the source-end of the corridor. He found that the experimental forward-front velocities could be predicted quite well with the expression

$$
v_{f}=0.9\left\{g \dot{q}^{\prime}\left(1+\Delta T_{m} / T_{\infty}\right) /\left(2 \rho_{\infty} c_{p} T_{\infty}\right)\right\}^{1 / 3}
$$

Ratios of his calculated to experimental front velocites for three experiments conducted in a $2.44 \mathrm{~m} \mathrm{x} 2.44 \mathrm{~m} \times 18.6 \mathrm{~m}$ corridor are plotted as unfilled symbols in Fig. 3. It is noteworthy that such good agreement is achieved even though the effects of heat transfer to the walls and ceiling of the corridor are neglected in Eq. (16).

Although experimental layer depths $(\delta)$ were also reported by Heskestad, corresponding predictions were not. Nevertheless, layer-depths could be easily calculated from the available data and Eq. (13). Ratios of calculated to experimental layer depths are shown in Fig. 4 (unfilled symbols).

Agreement is poor near the source-end of the corridor, but improves as the distance from the source, $x_{f}$, increases.

Heskestad's data also provide a limited means for checking Hinkley's analysis. It is important to note that, owing to heat losses to the source-room's 
surfaces, Heskestad reports values of ' $\dot{q}$ ' near the source-end of the corridor which increase with time; even for experiments using steady fire sources (e.g; $\dot{\mathrm{q}}_{\text {max }}^{\prime} / \dot{\mathrm{q}}_{\text {min }}^{\prime} \approx 3$ to 5 ). Hinkley's analysis, however, assumes constant $\dot{q}^{\prime}$ at the head-end of the corridor. Consequently, checks on $v_{f}$ and $\delta$ are limited to data taken when the front was at the head-end location; namely, the $5.3 \mathrm{~m}$ position in Figs. 3 and 4. Good agreement between experiment and theory (i.e., Eqs. $(2-4)$ ) is shown for this location in both figures. Indeed, agreement at the remaining downstream locations was found to be equally good but results are not plotted because the theory is not strictly applicable and agreement may be fortuitious. Nevertheless, further study of the curious agreement at downstream locations is recommended.

A fairly rigorous hydraulic model of transient ceiling flow is being developed by Emmons [9]. He is attacking the problem in pieces each of which can be validated. His analysis currently applies to adiabatic flows and accounts for hydraulic jumps that can occur depending on inlet conditions. The associated heat-transfer problem has been solved [10] and the solution will be added to the model in the near future. Emmons expects to produce a model in the form of a computer subroutine within the next year.

\section{RETURN GRAVITY CURRENT}

The return or reflected fire-induced gravity current has not been studied to the same extent as the forward current. Return waves have been measured, but theoretical models have not been developed.

Heskestad reports that the return waves in his experiments traveled at approximately constant depth and at approximately the same speed as the forward fronts. In the case of a steady 0.5 megawatt fire, he found the depth of the forward current to be 23 percent of the height of the corridor. The subsequent return wave increased the overall depth of the layer to 73 percent of the corridor height, thus leaving little clear space above the floor. This example illustrates that the height of the interface between the hot and cool layers in a corridor can change quickly.

Zukoski [1] has used the salt-water analog technique to study corridor flows in reduced-scale models. This technique actually models adiabatic flows and therefore foregoes study of heat transfer effects on the flow. Nevertheless, it provides an economical means for gaining insight into many flow phenomena. For example, Zukoski and Kubota [11] have found that for a given set of inlet conditions 1) the forward current moves essentially at constant velocity, 2) the return wave velocity is nearly constant at approximately 80 percent of that of the forward wave, and 3) the depth of the return wave is nearly equal to the depth of the forward wave; that is, with the passing of the return wave, the overall depth of the layer is almost doubled. Although this study was conducted on adiabatic gravity currents, findings 2) and 3) are consistent with Heskestad's findings for full-scale gravity currents with heat transfer (see previous paragraph).

Salt-water experiments [11] also revealed that the entire layer between the front of the return wave and the end wall was essentially stagnant (Fig. 5). 
This indicates that the return front is "fed" directly from the layer above. It is tempting to assume that the same phenomenum occurs for gravity currents with heat transfer. If this were true, then, as a first approximation (ignoring mixing at the front of the return wave), the temperature profile of the return layer could be equated with the temperature of the layer immediately above it (Eq. (9)). The temperature of the hot layer, both before and after the passage of the return front, would vary in the horizontal direction but not in the vertical direction. Unfortunately, the vertical temperature profile measured by Heskestad at the mid-length position of his corridor indicates that the return wave is markedly cooler and more stratified than the layer above it. Since Heskestad did not measure velocities in the layer behind the front, the presence of the "stagnant layer" cannot be confirmed or denied from his data. More work is required to resolve the "stagnant-layer" issue.

Indeed, the stagnant-layer behavior is quite different from the "overturning" and "sinuous" flows that Zukoski [1] observed during salt-water simulations of a fire plume in a room (Fig. 6). In the latter experiments, momentumdominated ceiling jets at the point of wall impingement produced overturning and a well-mixed upper layer, whereas buoyancy-dominated jets at the same point produced sinuous flow and a stratified layer. Zukoski argues that the existence of either momentum-dominated or buoyancy-dominated flow at the initial point of wall impingement is primarily a function of room geometry. He supports this position with the salt-water work of Baines and Turner [12] and Tangren et al [13]. Baines and Turner propose that the transition takes place when the ratio of lateral room dimension, $L$, to plume height, $H_{p}$, is between one and two (Fig. 7). Since this ratio is greater than two for typical corridors, sinuous flow and stratification would be expected. The discovery of the stagnant layer in the corridor flow further complicates the issue. Perhaps the stagnant layer is a consequence of the two-dimensional nature of the corridor flow, whereas the other phenomena arise from the threedimensional nature of the flow produced by an axis-symmetric plume centered in a room. In any event, the mechanisms which effect the character of the return wave as well as the overall stratification of the layer are not well understood at this time.

\section{UNIFORM FILLING}

In their salt-water experiments, Zukoski and Kubota find that once the reflected wave front reaches the head-end of the corridor, essentially uniform filling occurs throughout the corridor. Full-scale room/corridor experiments conducted by Cooper et al [14] exibited near-uniform filling of the corridor during most of the test period. Since the temperatures of the ceiling and walls of the corridor increase with time, the temperature of the gas layer would tend to become uniform during the uniform-filling period. Therefore, simple zone modeling of this portion of the process appears appropriate. Indeed, Cooper et al showed that the decent of the interface between the upper and lower layers in their room/corridor could be predicted reasonably well with a single-room zone model known as ASET [2]. In this case, the room/corridor combination was treated as one large room. 
ASET models the uniform-filling process depicted in Fig. 8. The room is closed except for a leakage path near the floor. The base of the fire is located a distance $\Delta$ above the floor and a distance $H$ beneath the ceiling. The heat release rate of the fire as a function of time, $\dot{Q}(t)$, is presumed to be known. The non-dimensional height of the interface above the base of the fire, $\zeta=Z_{i} / L_{c}$, and the non-dimensional temperature of the upper gas layer, $\phi=\mathrm{T}_{\mathrm{h}} / \mathrm{T}_{\mathrm{a}}$, are obtained as a function of non-dimensional time, $\tau=t / t_{c}$, by simultaneously solving the two differential equations [2]

$$
\begin{aligned}
& \mathrm{d} \zeta / \mathrm{d} r=-\left[\begin{array}{lc}
-c_{1} \dot{\mathrm{q}}-\mathrm{c}_{2} \dot{\mathrm{q}}^{1 / 3} \zeta^{5 / 3}, & 0<\zeta \leq \zeta_{0} \\
-c_{1} \dot{\mathrm{q}} & -\delta<\zeta \leq 0 \\
0, & \zeta=-\delta
\end{array}\right. \\
& \mathrm{d} \phi / \mathrm{d} \tau=\left[\begin{array}{ll}
\phi\left[c_{1} \dot{\mathrm{q}}-(\phi-1) \mathrm{c}_{2} \dot{\mathrm{q}}^{1 / 3} \zeta^{5 / 3}\right] /\left(\zeta_{0}-\zeta\right), & 0<\zeta<\zeta_{0} \\
\phi c_{1} \dot{\mathrm{q}} /\left(\zeta_{0}+\zeta\right), & -\delta \leq \zeta \leq 0
\end{array}\right.
\end{aligned}
$$

where

$L_{c}, t_{c}$, and $\dot{Q}_{c}$ are a characteristic length, time, and heat release rate, respectively,

A is the area of the floor,

$\lambda_{I}$ is the fraction of $\dot{Q}$ radiated from the combustion zone,

$\lambda_{c}$ is the fraction of $\dot{Q}$ conducted through the room's surfaces,

$\rho_{a}$ is the density of gas in the lower layer,

$\mathrm{T}_{\mathrm{a}}$ is the temperature of the lower layer,

$C_{p}$ is the specific heat of the gas in the lower layer,

$\varsigma_{0}=\mathrm{H} / \mathrm{L}_{\mathrm{c}} ; \quad \dot{\mathrm{q}}=\dot{\mathrm{Q}} / \dot{\mathrm{Q}}_{0} ; \quad \delta=\Delta / \mathrm{L}_{\mathrm{c}}$

$c_{1}=\left[\left(1-\lambda_{c}\right) \dot{Q}_{0} t_{c}\right] /\left(\rho_{a} C_{p} T_{a} A_{c}\right)$ 


$$
c_{2}=\left(0.210 t_{c} / A\right)\left\{\left[\left(1-\lambda_{I}\right) \dot{Q}_{0} g L_{c}^{2}\right] /\left(\rho_{a} C_{p} T_{a}\right)\right)^{1 / 3}
$$

ASET also predicts species concentrations via an equation similar to Eq. (18). Further details of the model and its applications can be found in [2].

Nelson [15] used ASET to estimate the filling of rooms connected by doorways to a corridor containing a hot gas layer. Each room was treated as a closed space (with a small leak at floor level) containing a virtual fire source that supplied energy at a rate equal to the enthalpy inflow through the doorway of the room. He estimated the mass flow through the vent using formulas from FIREFORM [16], which is a collection of convenient computational schemes for fire-safety applications. The same approach could be used to obtain a firstcut estimate of the uniform-filling of a corridor connected to a room containing a fire. A more refined estimate (based on fewer assumptions) could be obtained with a multiroom zone model such as FAST [3].

\section{RECOMMENDATIONS}

Although the current understanding of corridor flows is far from complete, several engineering formulas or models are available for estimating key phenomena. Since there is some empiricism associated with each of the gravity-current formulas, and since the experimental underpinings were obtained in moderate-length corridors (on the order of $20 \mathrm{~m}$ ), it should be understood that the formulas may not be valid for very long corridors. Bearing this in mind and assuming that $\dot{q}^{\prime}, \dot{m}$, and $T_{0}$ at the source-end of the corridor are known, it is recommended that estimates of corridor flow be made as follows:

\section{Initial Phase -. Forward Gravity Current}

* If the horizontal temperature profile, $\mathrm{T}(\mathrm{x})$, is not needed, use Heskestad's model (Eqs. $(13-14)$ ) to obtain $v_{f}$. This model appears to predict $v_{f}$ quite well, even when $\dot{q}^{\prime}, \dot{m}$, and $\mathrm{T}_{0}$ vary with time. Its shortcoming lies in the fact that the attendant $\delta$, which is defined by Eq. (13), may be incorrect by as much as a factor of three. However, since $\dot{m}$ is presumed to be known, another $\delta$ can be calculated from Eq. (4). One must recognize, however, that an inconsistency exists between the $\delta$ on the right side of Eq. (4) and the $\delta$ implicit in $v_{f}$ on the left side of the same equation. Also, numerical integration will be required to determine $x_{f}(t)$ when $\dot{q}$ ' varies with time.

* If $\mathrm{T}(\mathrm{x})$ is needed and $\dot{\mathrm{q}}^{\prime}, \dot{\mathrm{m}}$, and $\mathrm{T}_{0}$ are constant, use the appropriate form of Hinkley's model. The model for "warm" gas with heat transfer yields algebraic expressions for the lateral temperature gradient within the layer (Eq. (9)) as well as the position of the front (Eq. (6)). The model for "hot" gas with heat transfer (i.e., Eqs. $(9-11)$ ) is a more general extension of the "warm" model, but requires numerical integration to determine $x_{f}(t)$. 
* If $T(x)$ is needed and $\dot{q}^{\prime}, \dot{m}$, and $T_{0}$ are not constant, none of the models presented in this report apply. In this case, use average or maximum values for $\dot{q}^{\prime}, \dot{m}$, and $\mathrm{T}_{0}$ in conjunction with Eqs. $(9-11)$ to obtain average or worstcase conditions.

\section{Initial Phase -.- Return Gravity Current}

Little quantitative information is available for the return current.

Nevertheless, based on Heskestad's and Zukoski's work, use a simple first-cut model with the following features: 1) the front of the return current travels at 80 percent of the velocity of the forward front (or perhaps 80 percent of the average velocity of the forward front if it varies), 2) the depth of the return current is equal to the depth of the forward current (i.e. the depth of the hot layer is doubled upon passage of the return front), and 3 ) the lateral temperature profile in the return current is identical to that of the layer above it (i.e., no gradient in the hot layer in the vertical direction).

\section{Uniform-Filling Phase}

Once the return front reaches the head-end of the corrider, use a zone model such as ASET or FAST to calculate the uniform-filling process.

\section{REFERENCES}

1. Zukoski E.E., Fluid Dynamic Aspects of Room Fires, Fire Safety Science Proceedings of the First International Symposium, Hemisphere Publishing Corp., pp. 1-30, 1986.

2. Cooper, L.Y., A Mathematical Model for Estimating Available Safe Egress Time in Fires, Fire and Materials, 6 , Nos. 3\&4, pp. 135-144, September/December 1982.

3. Jones, W.W., A Multicompartment Model for the Spread of Fire, Smoke and Toxic Gases, Fire Safety Journal, , pp. 55-79, 1985.

4. Mitler, H.E., User's Guide to FIRST, A Comprehensive Single-Room Fire Model, Nat. Bur. Stand. (U.S.), NBSIR 87-3595, September 1987.

5. Heskestad, G., and Hil1, J.P., Propagation of Fire Smoke in a Corridor, Proceedings of the 1987 ASME-JSME Thermal Engineering Joint Conference, 1, March 22-27, 1987, Honolulu, HI, Amer. Soc. Mech. Eng., Marto, P.J. and Tanasawa, I., Editors, pp. 371-379, 1987.

6. Emmons, H.W., The Analysis of a Tradgedy, Fire Technology, 19, No. 2, May 1983.

7. Benjamin, T.B., Gravity Currents and Related Phenomena, J. Fluid Mechanics, 31, pp. 209-248, 1968. 
8. Hinkley, P.L., The Flow of Hot Gases Along an Enclosed Shopping Mall - A Tentative Theory, Fire Research Note No. 807, Fire Research Station, Borehamwood, Herts., March 1970.

9. Emmons, H.W., The Transient Ceiling Jet, Home Fire Project Technical Report No. 74, Harvard University, Cambridge, MA, August 26, 1986.

10. Alpert, R., Grant No. 60NANB5D0560; Quarterly Progress Report for Quarter February 28,1988 - May 27, 1988 "Prediction of Fire Dynamics", letter report to H. Mitler, NBS; Factory Mutual Research, Norwood, MA, July 8,1988 .

11. Zukoski, E.E., Kubota, T., Experimental Study of Environment and Heat Transfer in a Room Fire, Nat. Inst. Stand. Tech. (U.S.) NIST-GCR-88-554; November 1988 .

12. Baines, W.D., and Turner, J.J., "Turbulent Buoyant Convection from a Source in a Confined Region, J. Fluid Mechanics, 68, part 2, pp. 309-320, 1975.

13. Tangren, E.H., Sargent, W.S., and Zukoski, E.E., Hydraulic and Numerical Modeling of Room Fires, Jet Propulsion Center Report, California Institute of Technology, 1978.

14. Cooper, L.Y., Harkleroad, M., Quintiere, J., and Rinkinen, W., An Experimental Study of Upper Hot Layer Stratification in Full-Scale Multiroom Fire Scenarios, J. Heat Transfer, 104, pp. 741-749, November, 1982.

15. Nelson, H.E., An Engineering Analysis of Fire Development in the Hospice of Southern Michigan, December 15,1985, Proceedings of the Second International Symposium on Fire Safety Science, Tokyo, Japan, June 1988, (to be published).

16. Nelson, H.E., FIREFORM - - A Computerized Collection of Convenient Fire Safety Computations, Nat. Bur. Stand. (U.S.), NBSIR 86-3308, 1986. 


\section{NOMENCLATURE}

A area of floor of room

C empirical constant $(\approx 0.8)$

$\mathrm{C}_{\mathrm{p}}$ specific heat of gas in room's lower layer (ASET)

$c_{1}$ defined by Eq. (19)

$\mathrm{c}_{2}$ defined by Eq. (20)

$c_{p}$ specific heat of air

$\mathrm{g}$ gravitational acceleration

$\mathrm{H}$ height of corridor or distance between base of fire and ceiling (Fig. 8)

$\mathrm{H}_{\mathrm{p}}$ height of plume (Fig. 7)

$h^{p}$ heat transfer coefficient

$\mathrm{K}$ defined by Eq. (7)

L lateral room dimension

L.c characteristic length (usually set at $0.3 \mathrm{~m}$ )

$\dot{\mathrm{m}}$ mass injection rate into ceiling layer

$\dot{Q}$ heat release rate of fire

$\dot{Q}_{c} \quad$ characteristic heat release rate (usually set to $\dot{Q}$ at $t=0$ )

$\dot{\mathrm{q}} \quad \dot{\mathrm{Q}} / \dot{\mathrm{Q}}_{0}$, normalized heat release rate

$\dot{q}^{\prime}$ convective heat injection rate per unit width into ceiling layer

$t$ time

$t_{c}$ characteristic time (usually set at 1 second)

$\mathrm{T}$ temperature of gravity current or layer

$\mathrm{T}_{\mathrm{a}}$ temperature of room's lower layer (ASET)

$\mathrm{T}_{\mathrm{h}}$ temperature of room's hot layer (ASET)

$\mathrm{T}_{0}$

$T_{\infty}$

$\Delta \mathrm{T}$

$\Delta \mathrm{T}_{\mathrm{m}}$ maximum temperature rise measured in ceiling layer at source-end of corridor

$U^{\prime}$ characteristic velocity defined by Eq. (3)

$v_{0}$ speed of flow into ceiling layer at source-end of corridor (Fig. 2)

$v_{f} \quad$ propagation speed of forward gravity current

$v_{r} \quad$ propagation speed of return gravity current

W width of corridor

$\mathrm{x}$ lateral coordinate

$x_{0} \quad$ lateral coordinate of point of injection of flow into ceiling

layer (Fig. 2)

$\mathrm{x}_{\mathrm{f}} \quad$ lateral coordinate of forward gravity-current front (Fig. 2)

$\mathrm{Z}_{\mathrm{i}}$ height of gas-layer interface above base of fire (Fig. 8)

$\Delta$ height of base of fire above floor (Fig. 8)

$\delta$ depth of gravity current or layer; or $\Delta / L_{c}$, nondimensional height of base of fire above floor

$\zeta \quad Z_{i} / L_{c}$, nondimensional height of gas-layer interface above base of fire

$\zeta_{0} \mathrm{H} / \mathrm{L}_{\mathrm{c}}$, nondimensional distance between base of fire and ceiling

$\lambda_{c}$ fraction of $\dot{Q}$ conducted through the room's surfaces

$\lambda_{r}$ fraction of $\dot{Q}$ radiated from the combustion zone

$\xi$ defined by Eq. (1la)

$\rho$ density of gravity current or layer

$\rho_{\mathrm{a}}$ density of room's lower layer (ASET)

$\rho_{0}$ density of gas injected into ceiling layer at $x_{0}$ 
$\rho_{\infty}$ density of ambient air

$\Delta \rho \quad \rho_{\infty}-\rho$, density deficiency

$\tau \quad t / t_{c}$, nondimensional time

$\phi \quad \mathrm{T}_{\mathrm{h}} / \mathrm{T}_{\mathrm{a}}$, nondimensional temperature in upper gas layer 

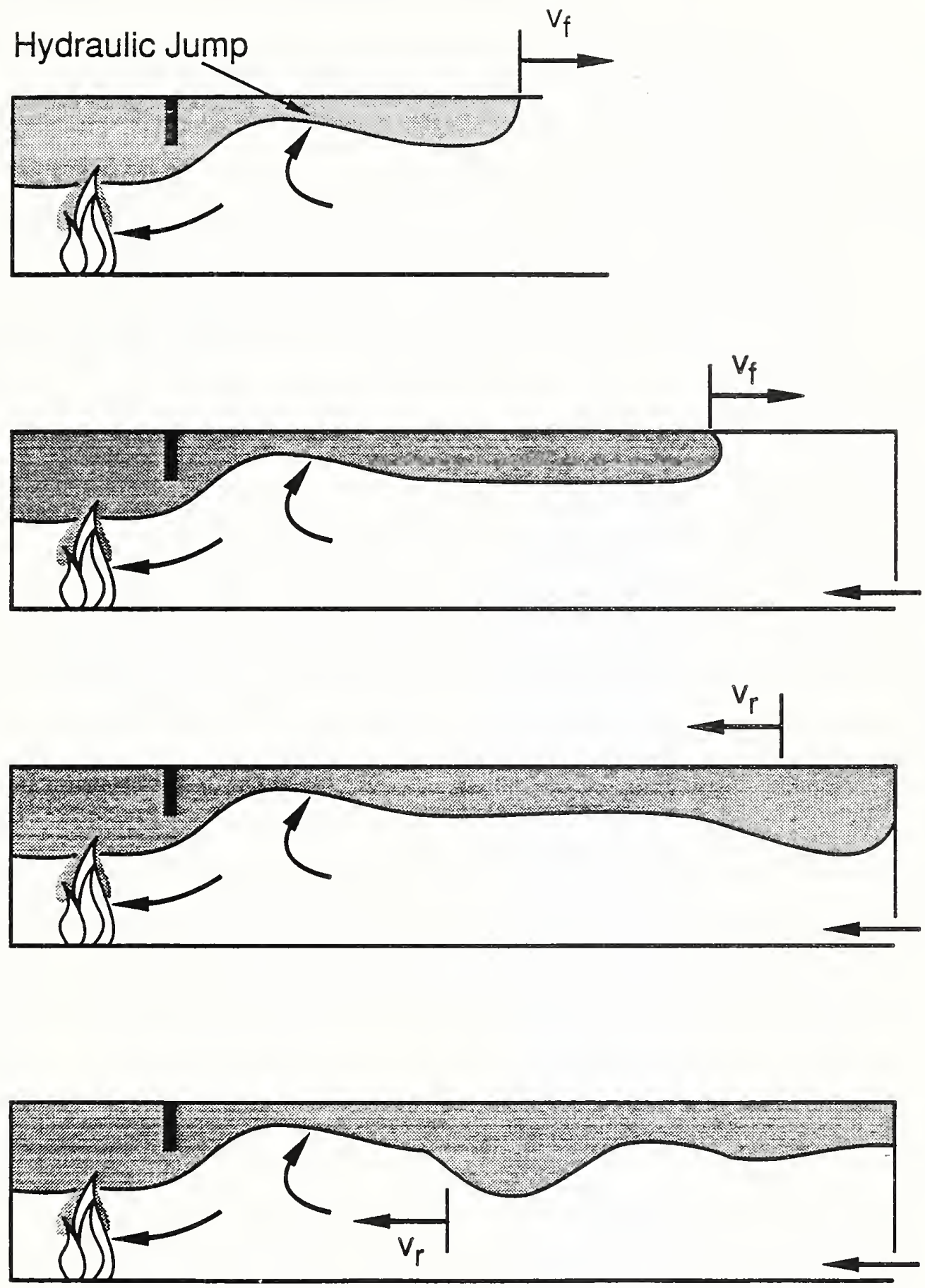

ت

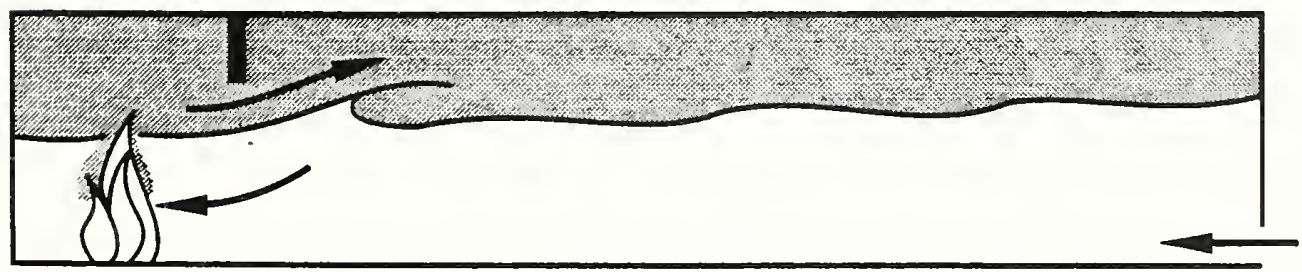




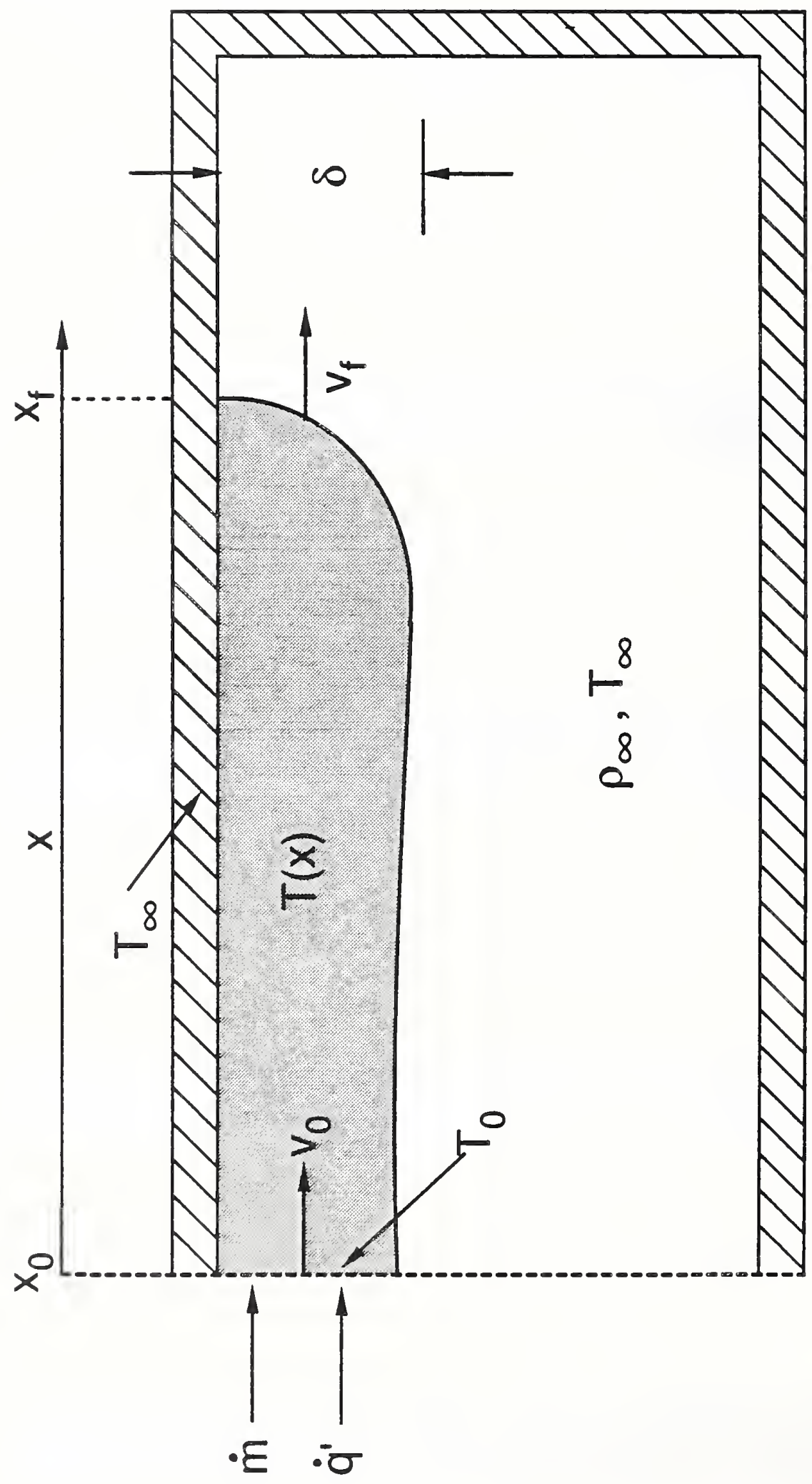

告 


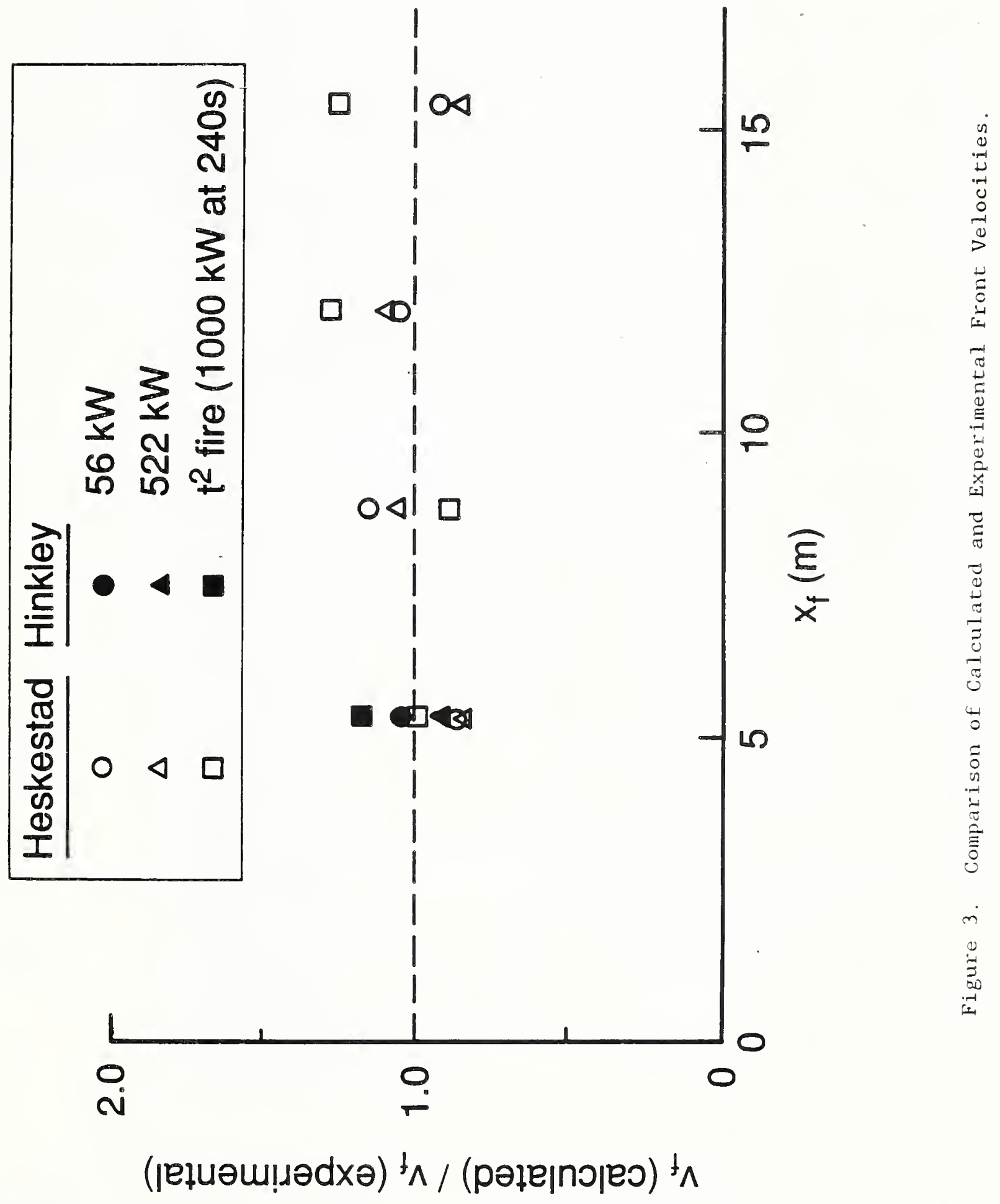




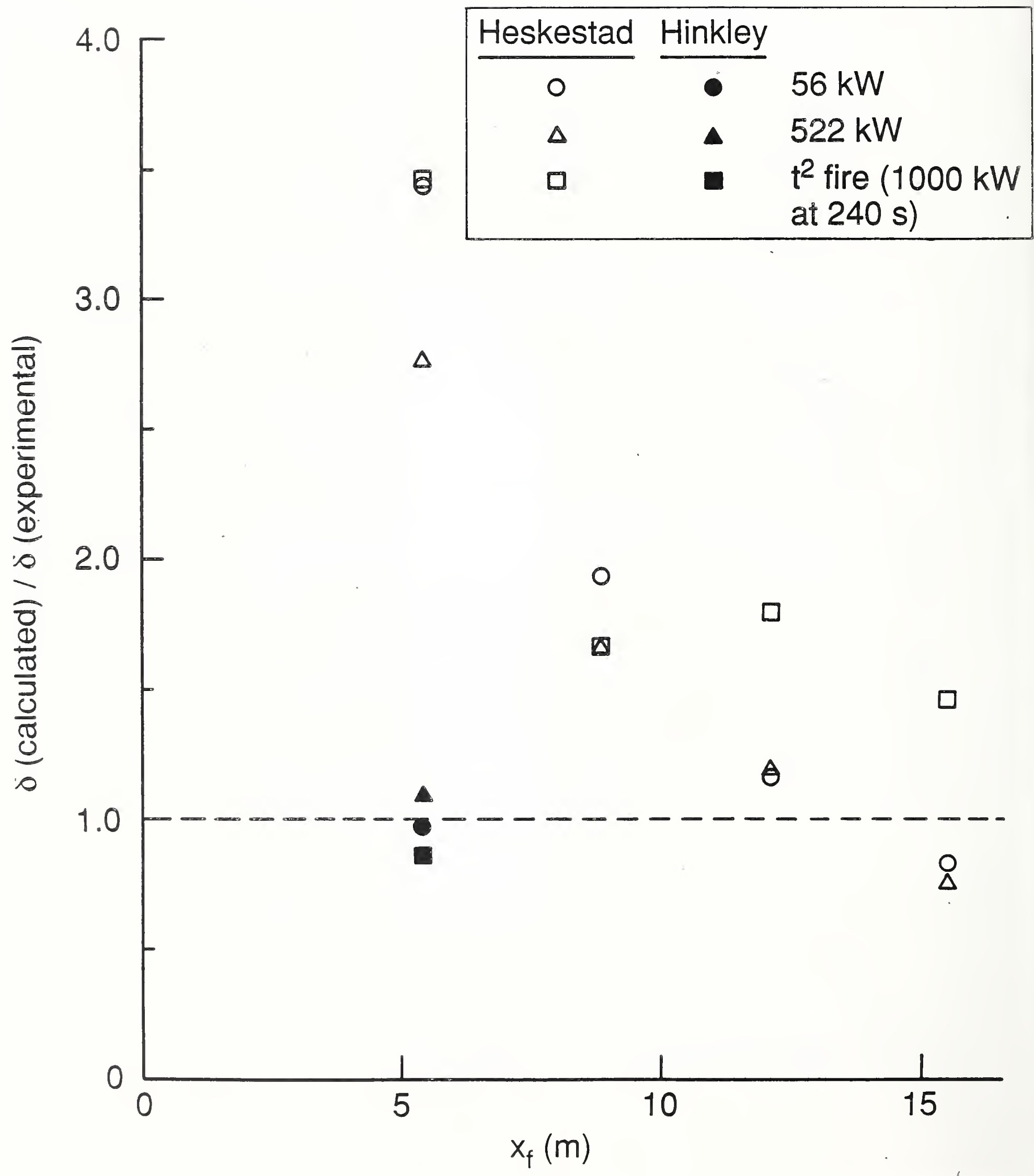

Figure 4. Comparison of Calculated and Experimental Thickness of Forward Gravity Current. 


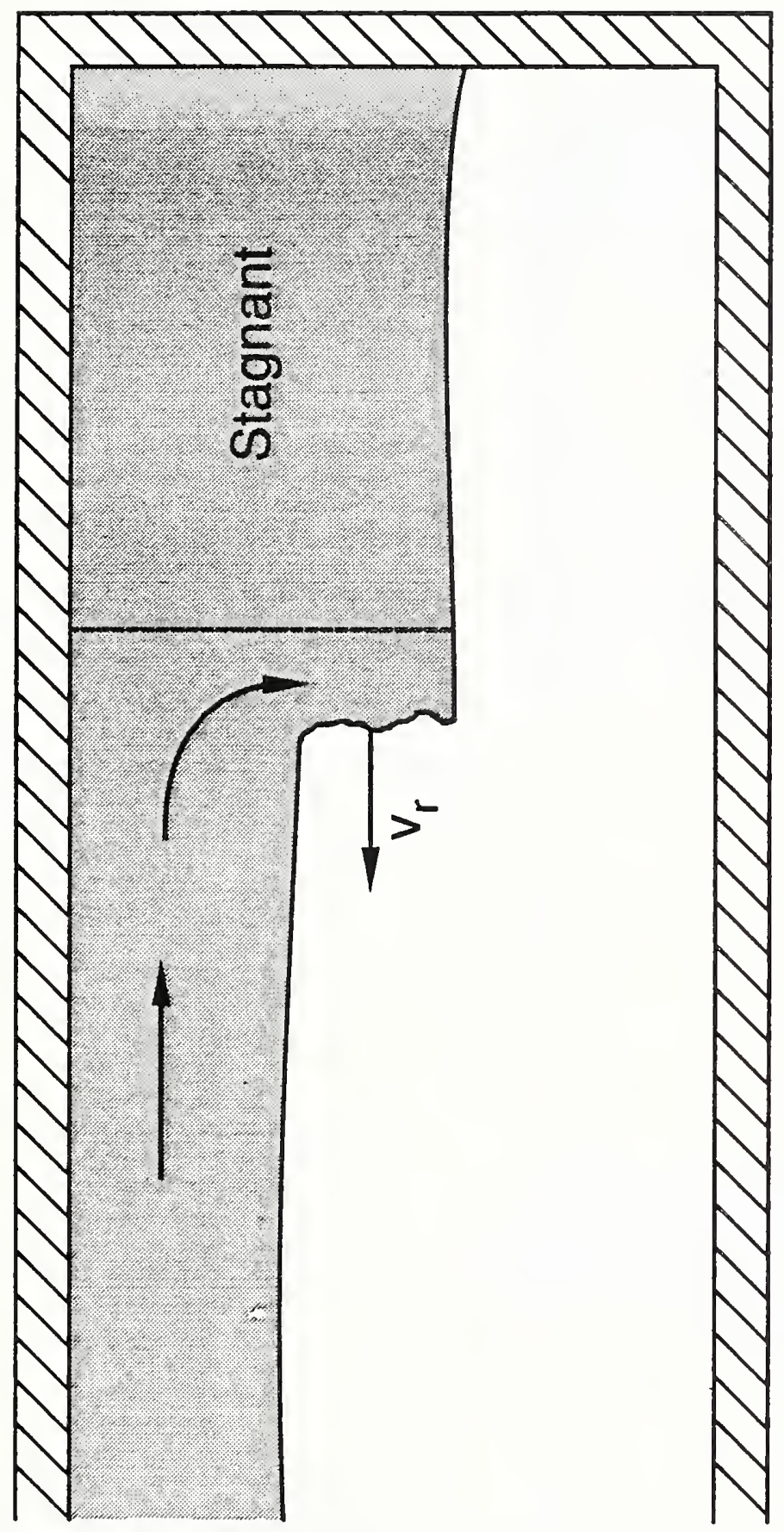

 


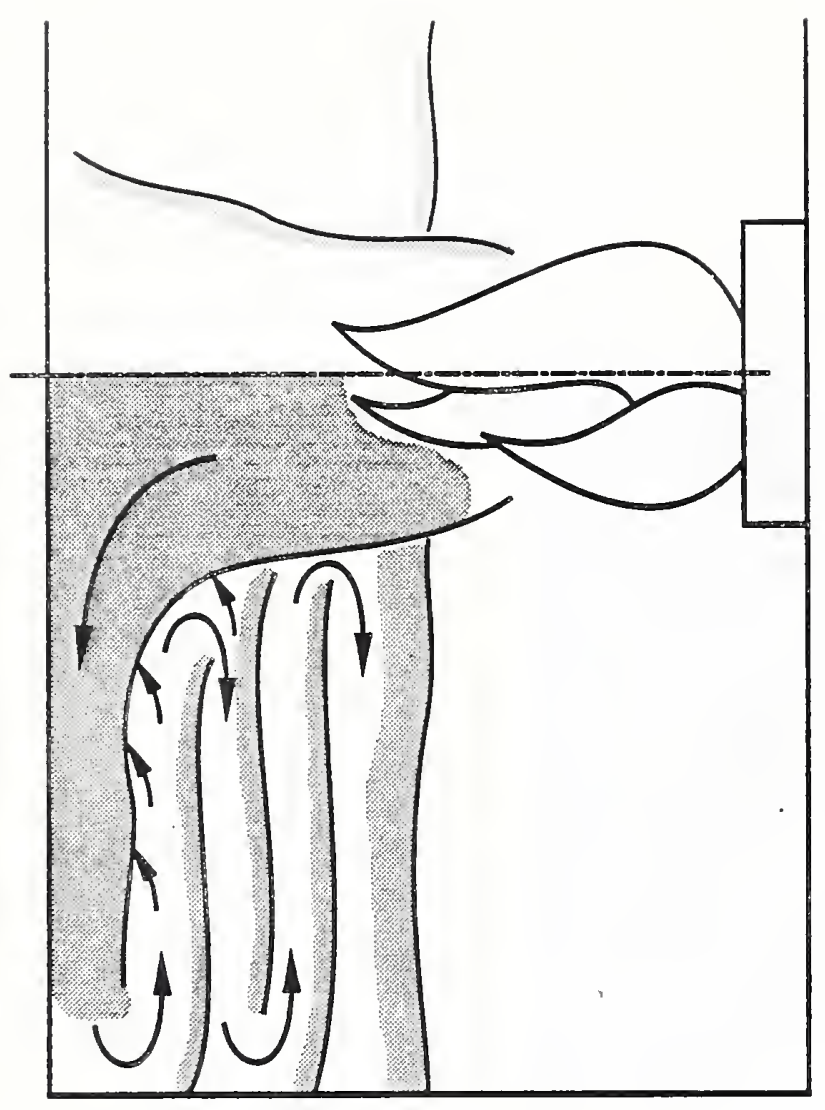

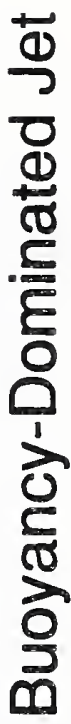

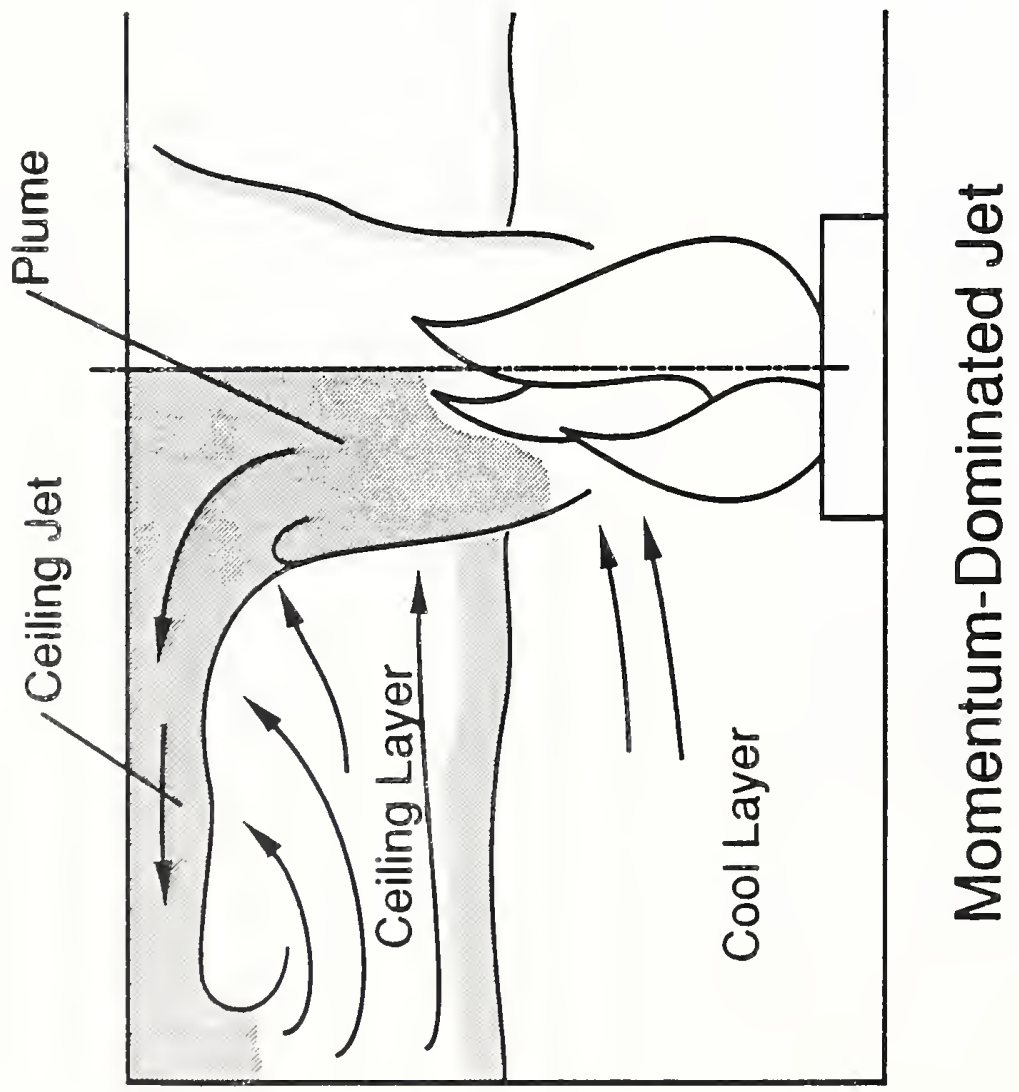




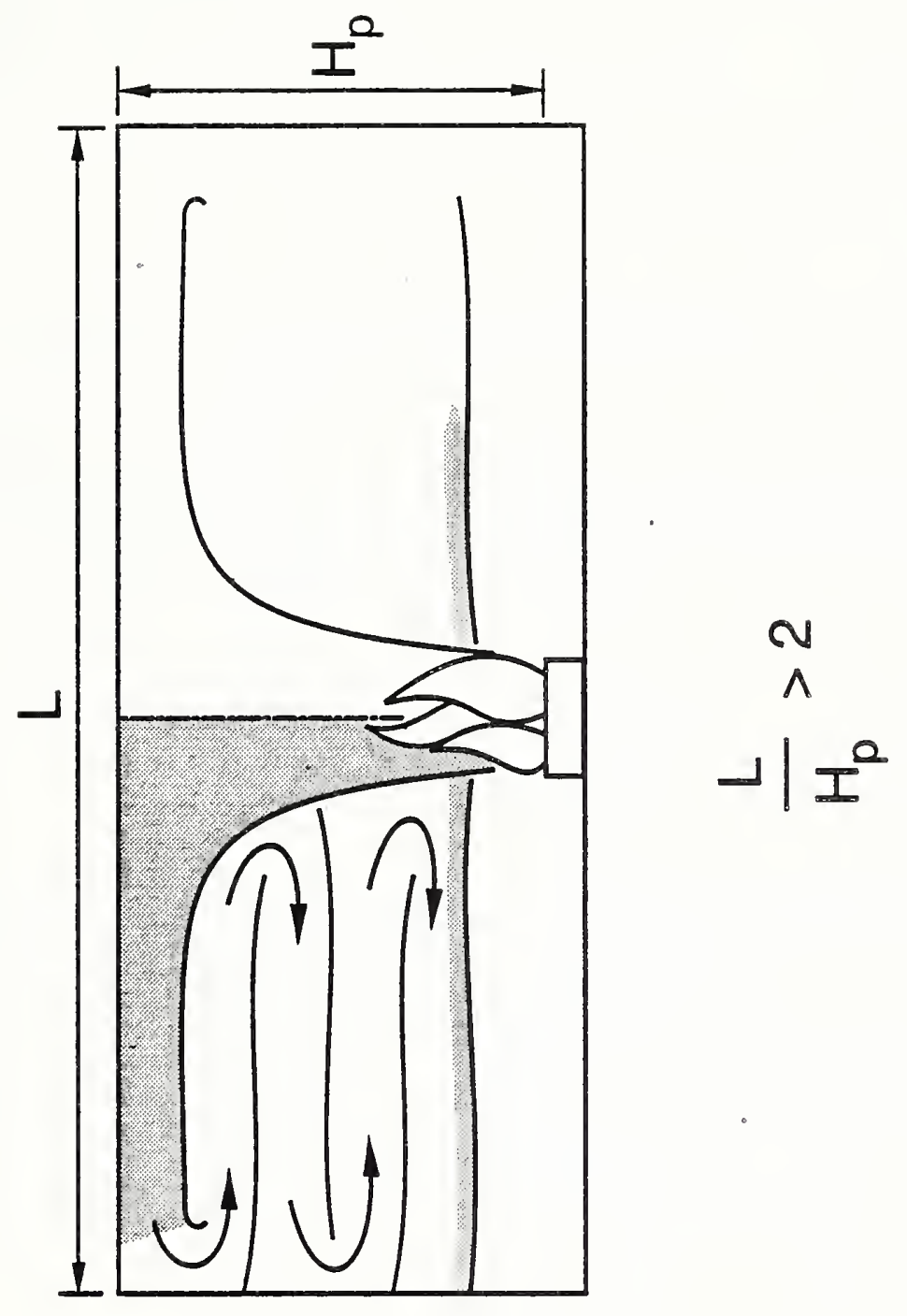

تే

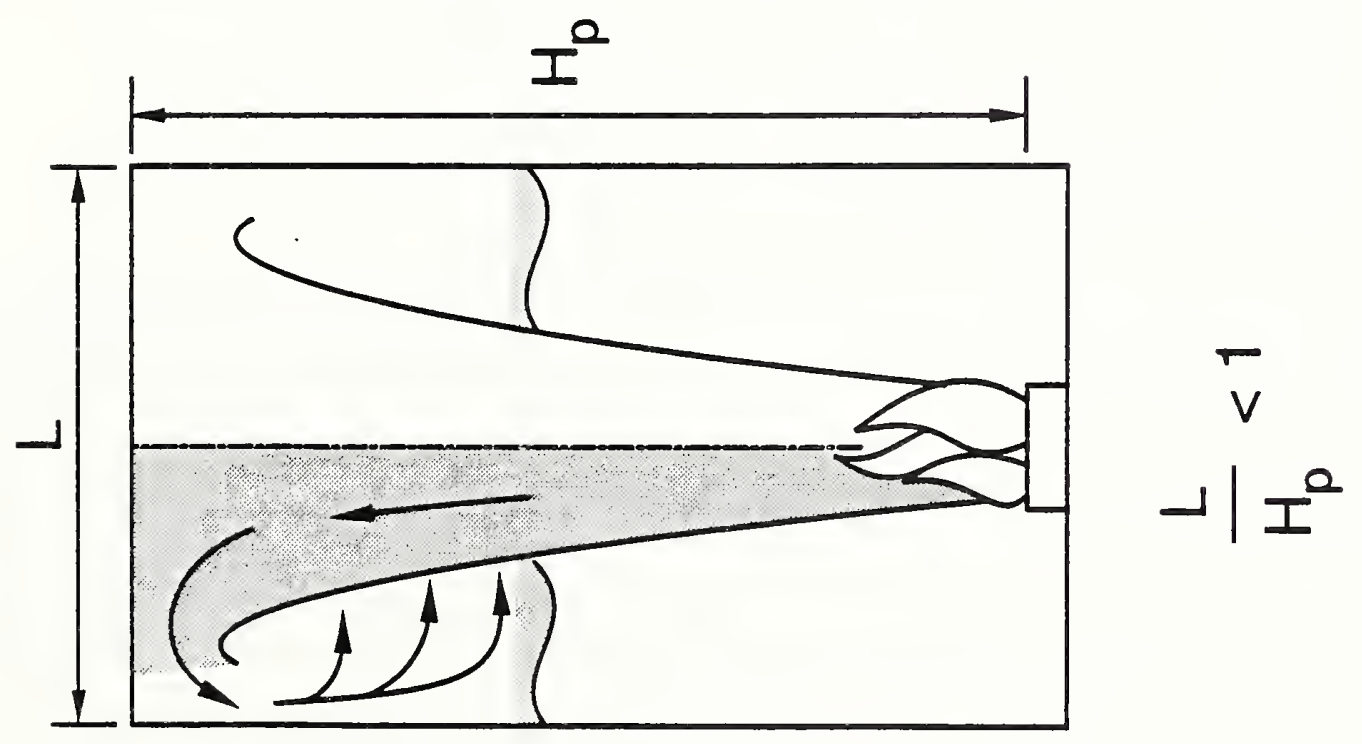




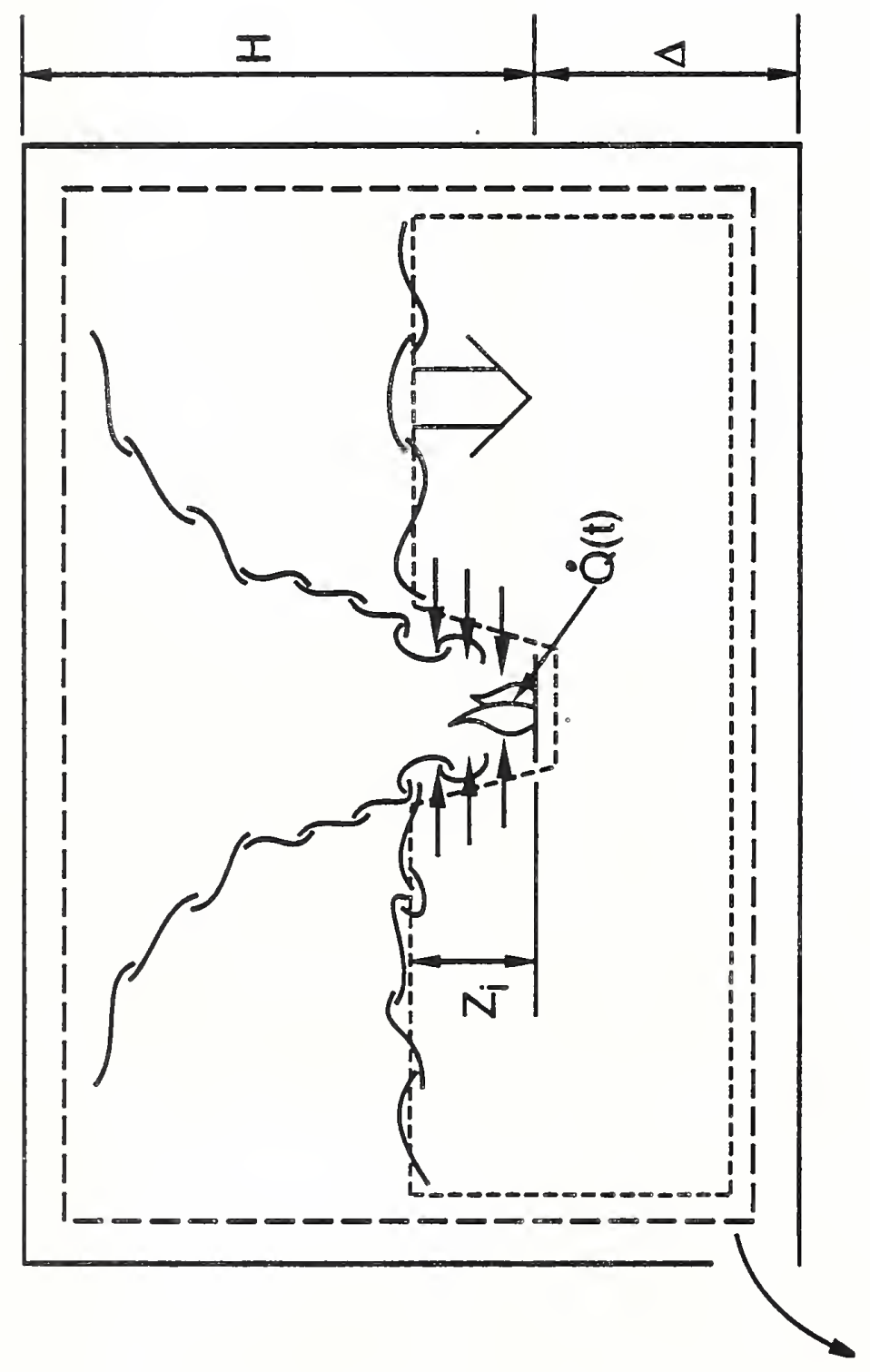

D 
4. TITLE AND SUBTITLE

Fire Induced Flows in Corridors -- A Review of Efforts to Model Key Features

5. AUTHOR(S)

K.D. Steckler

6. PERFORMING ORGANIZATION (If joint or other than NBS, see instructions)

7. Contract/Grant No.

National Institute of Standards

\& Technology

U.S. Department of Commerce

Gaithersburg, MD 20899

9. SPONSORING ORGANIZATION NAME AND COMPLETE ADDRESS (Street, City。 State, ZIP)

General Services Administration

Washington, DC 20405

10. SUPPLEMENTARY NOTES

Document describes a computer program: SF-185. FIPS Software Summary, is attached.

11. ABSTRACT (A 200-word or less factual summary of mose significane information. If documene includes a significant bibliogrophy or literoture survey. mention it here)

A literature review was undertaken to identify engineering formulas or models which can be used to predict key features of the corridor-filling process. The results of that review are presented and assessed. The filling process is viewed as a series of three events: a forward gravity current moving away from the fire source, a reflected or return gravity current moving toward the source, followed by uniform filling of the entire corridor. Recommendations for estimating the filling during each of these stages are presented.

12. KEY WORDS (Six to twelve entries; alphobetical order; capitalize only proper names; and separate key words by semicolons) corridors; flow fields; gas flow; mass flow; models; propagation velocity

13. AVAILABILITY

X Unlimited

For Official Distribution. Do Not Release to NTIS

Order From Superintendent of Documents, U.S. Government Printing Office, Washington. D.C. 20402.

X Order From National Technical Information Service (NTIS). Springfield, VA. 2216I
14. NO. OF

PRINTED PAGES

25

15. Price

$\$ 9.95$ 
